\title{
Fixation of Mandibular Body Fracture with Combination of One-Piece Cast Splint and Miniplate
}

\author{
Fuminori Katou and Katsutoshi Motegi \\ Department of Oral and Maxillofacial Surgery 1, Tohoku \\ University School of Dentistry, Sendai 980-77
}

\begin{abstract}
Katou, F. and Motegr, K. Fixation of Mandibular Body Fracture with Combination of One-Piece Cast Splint and Miniplate Tohoku J. Exp. Med., 1995, 175 (2), 111-121 — A method for fixation of mandibular body fracture within the dental arch using a combination of a rigid one-piece cast splint and a pliable miniplate screwed at the inferior border of the mandible was developed with the highest priority placed on restoration of occlusion. This paper presents the results obtained in 36 patients treated by this method. The postoperative occlusion was analyzed using the T-scan system in 20 fully dentate patients without major caries. The data obtained in the patients were well comparable to those in normal subjects. —_ cast splint; osteosynthesis; miniplate; T-scan system
\end{abstract}

Since 1970s, surgical treatment for mandibular fracture has rapidly progressed by the introduction of an $\mathrm{AO}$ plate. An $\mathrm{AO}$ plate has originally been developed by orthopedists to relieve patients from postoperative external fixation by rigid fixation of a fractured extremity using this plate. Due to its large thickness and size, some disadvantages were involved; the need for an extraoral approach and the technical difficulty in surgery (Spiessl 1989; Lindqvist 1992). A miniplate, smaller in size and thus more appropriate for application to maxillofacial bones, has been developed later. This has been introduced together with dynamic data corroborating the sufficient fixation strength obtained by fixation with a miniplate (Champy et al. 1976). The technical facileness and the advantage of avoiding the formation of a facial scar by an intraoral approach have encouraged extensive application of this plate. However, doubts have been raised on whether the miniplate could maintain accurate occlusion without application of intermaxillary fixation (Mommaerts and Engelke 1986; Raveh et al. 1987; Kroon et al. 1991; Schmelzeisen et al. 1992).

We developed a method for fixation with the highest priority placed on restoration of occlusion, using a combination of a rigid one-piece cast splint for

Received June 30, 1994; revision accepted for publication October 24, 1994.

Address for reprint: Fuminori Katou MD, DDS, Department of Oral and Maxillofacial

Surgery 1, Tohoku University School of Dentistry, 4-1 Seiryo-machi, Aoba-ku, Sendai 98077, Japan. 
reduction and fixation of the dentition and a pliable miniplate at the inferior border of the mandible for fixation of the fractured bone fragments (Katou 1988). The purpose of this paper is to review patients with mandibular body fracture treated by this method and to report the evaluation of postoperative occlusion.

\section{Treatment Procedure}

A study model is prepared as early as possible after examination of the patient. The model is sawn along the fracture line. Model operation is then carried out. A one-piece cast splint is prepared for the dentition on which model opeartion was performed. The splint measures $1 \mathrm{~mm}$ in thickness and $2 \mathrm{~mm}$ in width and is made of cobalt-chromium. The splint is ligated on the teeth under local anesthesia. The fragments are guided to the position of reduction by tightening the wire (Figs. 1 and 2). If reduction is not achieved by this single process, intermaxillary elastic traction is applied, and the wire is tightened when the fragments are reduced to individual normal occlusal positions. After the occlusion is reduced by the one-piece cast splint, the fragments are fixed with a miniplate at the inferior border of the mandible by an intraoral approach (Fig. 3). Intermaxillary fixation was not used postoperatively.

\section{Materials and Methods}

During 4 years and 4 months from January, 1989 to April, 1993, 36 patients (24 males, 12 females) aged 15-44 years (mean age 21.3) with mandibular body fracture within the dental arch were treated by our method at the Department of

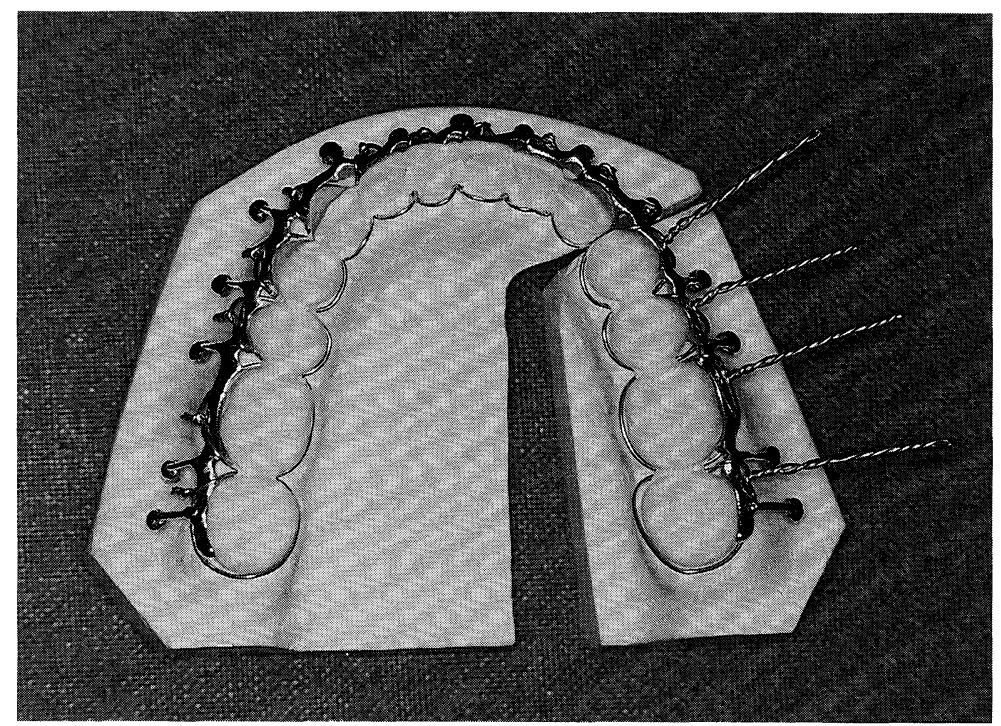

Fig. 1. Procedure for reduction of bone fragments with a one-piece cast splint on a study model. 


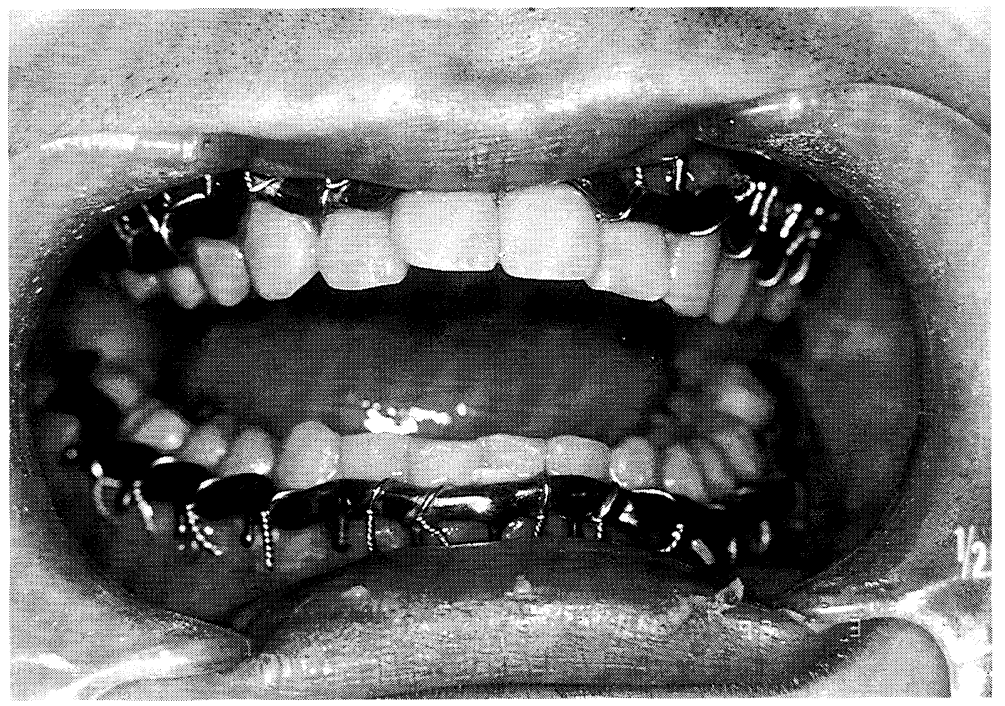

Fig. 2. Reduction with a one-piece cast splint in a patient with mandibular body fracture.

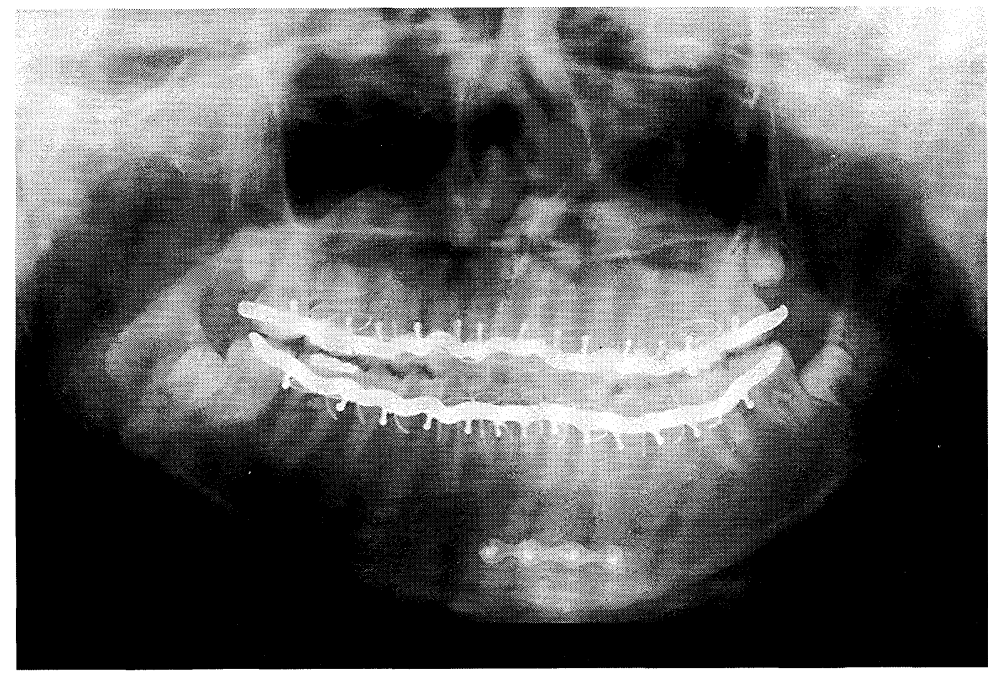

Fig. 3. Panoramic radiograph showing fixation with a one-piece cast splint and a miniplate at the inferior border of the mandible. (Same patient as in Fig. 2)

Oral and Maxillofacial Surgery 1, Tohoku University School of Dentistry. Twenty one patients had two line fracture and 15 had one line fracture. The injury-to-treatment interval was 1.5 days (mean). The one-piece cast splint was fitted at 9.5 days (mean) after the injury. Fixation of the fragments was carried 
out at 13.2 days (mean) after the injury. The cast splint was removed approximately 6 weeks after operation.

The postoperative occlusion was evaluated in 20 fully dentate patients having neither defect of any tooth from the central incisors to the second molars nor major caries. This series of patients ranged in age from 15 to 28 years with the mean age of 19.3 years. The T-scan system (Tekscan Inc., Boston, MA, USA) developed in 1987 by Maness et al. was used for the evaluation of the postoperative occlusion in these patients 6-36 months postoperatively. The T-scan system has a horseshoe-shaped pressure sensor of $120 \mu \mathrm{m}$ in thickness and provides real time information on the positions of tooth contacts and strength of pressure at the contact points. It is an apparatus which allows quantitative analysis of occlusal contacts by soft-ware processing. The evaluation of the postoperative occlusion was based on the force of occlusion at intercuspal positions (Fig. 4). The mean values of four repeated measurements were used.

Left force (LF) is the sum of occlusal forces at the occlusal contacts on the left side. Right force (RF) represents the corresponding value on the right side. Left- right moment (LRM) is the sum of the products of the occlusal forces at all contact points and the distances from the midsagittal axis and represents the balance of occlusal forces between the left and right sides. The value on the left side was indicated with a + symbol and that on the right with a-symbol. Left lever (LL) represents the anteroposterior balance of the occlusal contacts on the left side as expressed by the distance from the incisal axis. Right lever (RL) represents the corresponding value on the right side (Fig. 5).

\section{Results}

\section{Review of patients}

Panoramic radiograph confirmed satisfactory bony union in all the 36 patients. Nonunion or delayed union was detected in none of them. Exposure

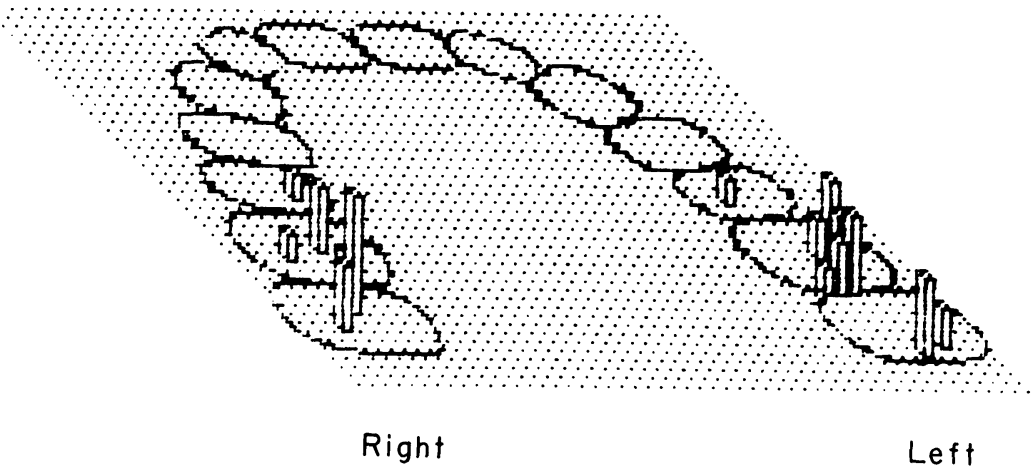

Fig. 4. Three-dimensional presentation of occlusal force distribution in analysis with T-scan system. 


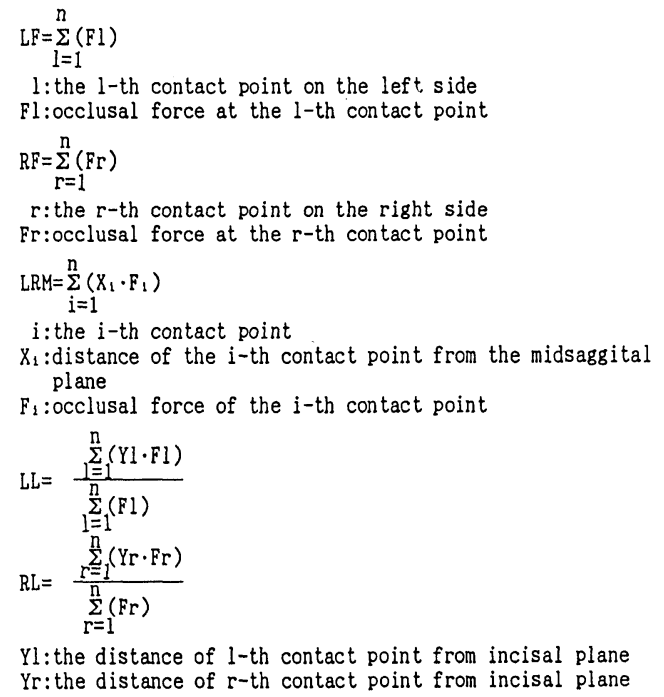

Fig. 5. Calculation method of statistical data for occlusal forces using T-scan system.

TABLE 1. Complication rates in our cases and those of other authors

\begin{tabular}{|c|c|c|c|c|c|c|}
\hline & \multirow[b]{2}{*}{$\begin{array}{c}\text { Number } \\
\text { of } \\
\text { cases }\end{array}$} & \multicolumn{5}{|c|}{ Rates of complications ( $\%)$} \\
\hline & & Infection & $\begin{array}{l}\text { Delayed } \\
\text { union }\end{array}$ & $\begin{array}{l}\text { Nonunion } \\
\text { or } \\
\text { Pseudarth- } \\
\text { rosis }\end{array}$ & Malocclusion & $\begin{array}{c}\text { Wound } \\
\text { dehiscence }\end{array}$ \\
\hline Our cases & 36 & 0 & 0 & 0 & 0 & 0 \\
\hline $\begin{array}{c}\text { Champy et al. } \\
(1978)\end{array}$ & 183 & 3.8 & 0.5 & 0.5 & 4.8 & 0.5 \\
\hline $\begin{array}{l}\text { Mommaerts } \\
\text { \& Engelke } \\
\text { (1986) }\end{array}$ & 41 & 12 & n.m. ${ }^{a}$ & n.m. ${ }^{a}$ & 7.3 & n.m. ${ }^{a}$ \\
\hline $\begin{array}{l}\text { Raveh et al. } \\
\quad(1987)\end{array}$ & 367 & 0.5 & 0 & 1.7 & 0.5 & n.m. ${ }^{a}$ \\
\hline $\begin{array}{l}\text { Dodson et al. } \\
(1990)\end{array}$ & 39 & 17.9 & 0 & 0 & 7.7 & n.m. ${ }^{a}$ \\
\hline
\end{tabular}

a Not mentioned in the report.

of the plate, dehiscence, purulent discharge or a sign of infection like osteomyelitis was also detected in none (Table 1). None of the patients needed extraction of teeth, removal of the plate or additional intermaxillary fixation postoperatively. 


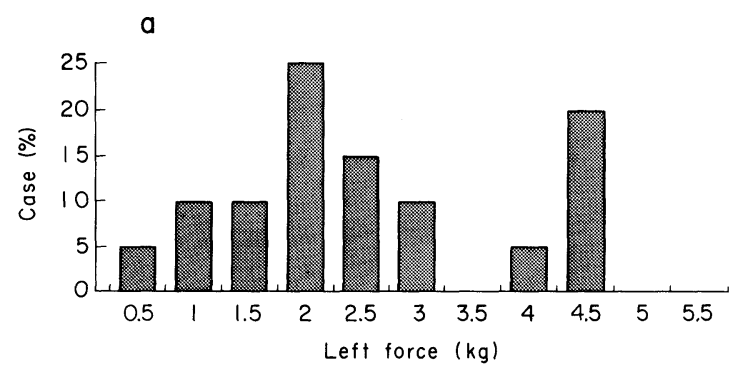

$b$

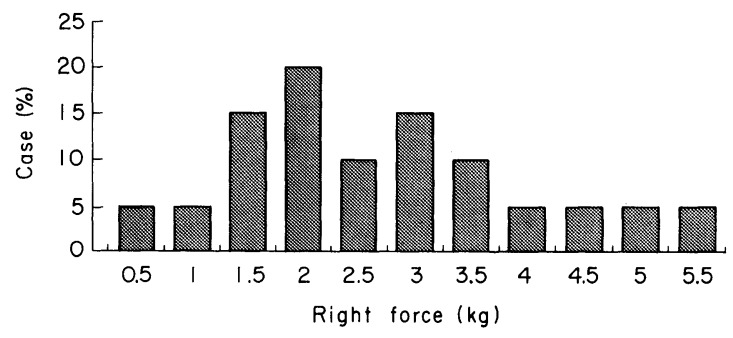

Fig. 6. Histograms showing distributions of left (a: mean 2.41, s.D. \pm 1.22 ) and right (b: mean 2.49, S.D. \pm 1.39 ) forces.

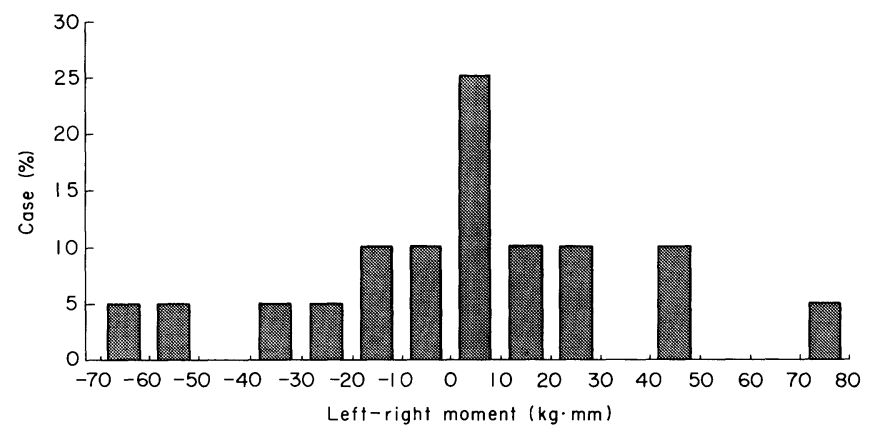

Fig. 7. Histogram showing left-right moment (mean 2.01, S.D. \pm 32.9 ).

\section{Evaluation of occlusion}

The mean values of left forces was 2.41 (S.D. \pm 1.22 ) $\mathrm{kg}$ and that of right forces 2.49 (S.D. \pm 1.39 ) kg. In statistical paired $t$-test of the mean values of left and right forces, $t=0.63$ ( $p>0.53$ ) was obtained, and thus the mean values on the left and right sides were statistically found almost equal (Fig. 6). The mean value of left-right moment was 2.01 (s.D. \pm 32.9$) \mathrm{kg} \cdot \mathrm{mm}$. In one-sample normality analysis to examine how the left-right moment data fit in a normal curve, $t=0.27$ $(p>0.78)$ was obtained. This indicates that the occlusal contacts on the left and right sides were almost symmetrically balanced (Fig. 7). The mean value of left 

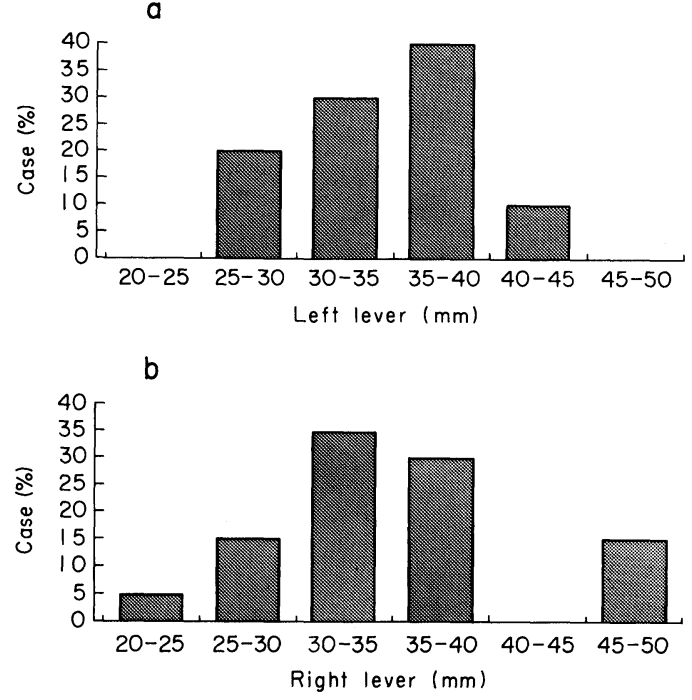

Fig. 8. Histograms showing left (a: mean 34.6, s.D. \pm 4.64 ) and right (b: mean 35.3 , s.D. \pm 7.19$)$ levers.

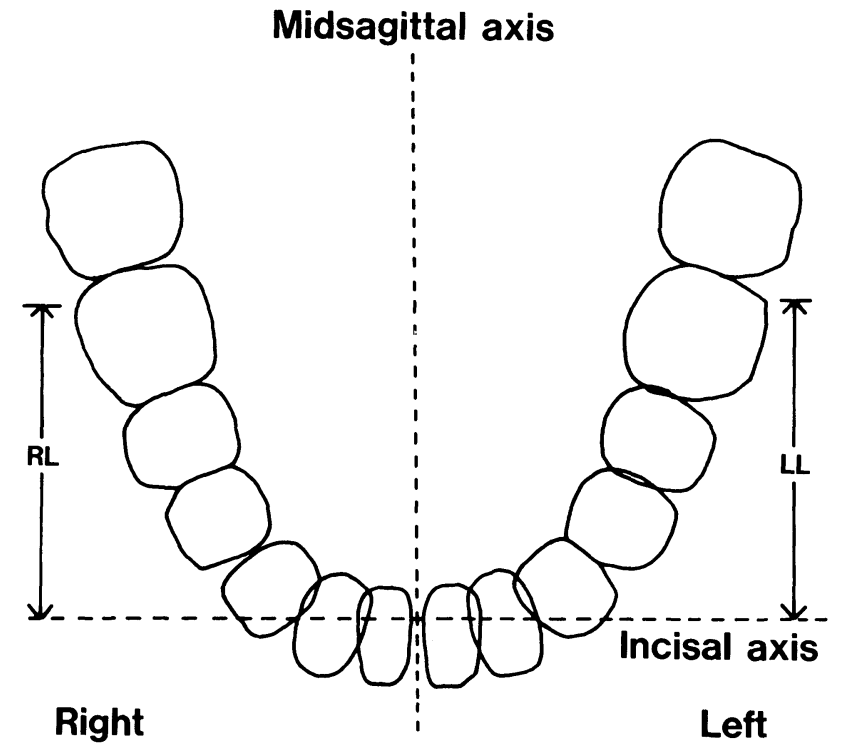

Fig. 9. Schematic presentation of left and right levers; projection on occlusal plane. 
TABLE 2. Summary of $L F, R F, L R M, L L$ and $R L$ statistics

\begin{tabular}{llc}
\hline Test & Mean & S.D. \\
\hline LF & $2.41 \mathrm{~kg}$ & $1.22 \mathrm{~kg}$ \\
RF & $2.49 \mathrm{~kg}$ & $1.39 \mathrm{~kg}$ \\
LRM & $2.01 \mathrm{~kg} \cdot \mathrm{mm}$ & $32.9 \mathrm{~kg} \cdot \mathrm{mm}$ \\
LL & $34.6 \mathrm{~mm}$ & $4.64 \mathrm{~mm}$ \\
RL & $35.3 \mathrm{~mm}$ & $7.19 \mathrm{~mm}$ \\
\hline LF vs. RF & $t=0.63, p>0.53$ & \\
LRM vs. perfect & $t=0.27, p>0.78$ & \\
LL vs. RL & $t=0.54, p>0.59$ & \\
& &
\end{tabular}

leverand right lever were 34.6 (S.D. \pm 4.64$) \mathrm{mm}$ and 35.3 (s.D. \pm 7.19 ) $\mathrm{mm}$, respectively. The statistical values of these parameters were likewise compared by $t$-test. $t=0.54(p>0.59)$ was obtained. This indicates that the values were almost equal on both sides (Fig. 8 and Table 2). Fig. 9 shows that the left and right levers were positioned at the first molars on the occlusal plane.

\section{Discussion}

This study was designed to demonstrate that the occlusion in the patients with fractured mandible reduced and fixed with the one-piece cast splint and miniplate was satisfactorily restored postoperatively. With the introduction of a concept of immediate function, namely, early reconstruction of the function by rigid internal fixation which was begun with the development of an AO plate, the treatment of mandibular fracture has undergone rapid progresses. The perception that a miniplate could provide a sufficient amount of strength for fixation of small bones such as maxillofacial bones is magnificient (Champy et al. 1976). However, doubts as to whether fractured bone fragments fixed with only a miniplate could maintain correct occlusion, have been raised not only by an maxillofacial surgeon who preferred the use of a thick and hard plate for rigid internal fixation (Raveh et al. 1987) but also by those who have undertaken a series of miniplate osteosynthesis (Mommaerts and Engelke 1986; Kroon et al. 1991; Schmelzeisen et al. 1992). Intraoperative determination of occlusion seems in some cases to have been undertaken in rather an unsophisticated manner; for example,during surgery the bone fragment was manually held before plate fixation by an assistant to the centric occlusal position (Cawood 1985) or inter maxillary fixation (IMF) was carried out by a simple technique using Ernst ligatures (Schmelzeisen et al. 1992). It appears as if complication-free bony union constituted the major purpose of operation and restoration of occlusion were of secondary importance. In our opinion, bony union in the fractured mandible can be achieved even if the fixation is loose. Therefore, we consider it most important that the reduced occlusion is maintained against masticatory muscle 
power until bony union is completed. With this view in mind, we developed the present method by which the occlusion reduced is maintained with a rigid one-piece cast splint and the fractured fragments are fixed with a flexible miniplate.

The occurrence of a gap between bone fragments due to underbending or overbending of the plate applied for fixation has been described even for pliable miniplates in an in vitro study (Kroon et al. 1991). If the plate is bent perfectly to fit to the mandible, bone fragments would stay at the reduced position and the occlusion may be maintained at a normal position. However, it is technically difficult to ensure always well-fit bending. The use of AO plates is still more difficult. It has been described that rigid fixation with $\mathrm{AO}$ plates was a difficult, unforgiving procedure with no exception, and refraining from this operation has been recommended, unless at a trauma center which is experienced with hundreds of cases of fixation every year (Lindqvist 1992).

Dodson et al. (1990) described that rigid internal fixation gave rise to a high frequency of malocclusion and found the occurrence of malocclusion in $3(7.7 \%)$ of their 39 cases. He attributed this to the imperfect adapation to the mandible. Champy et al. (1978) found malocclusion in $4.8 \%$ of their patients and Cawood (1985) in 8\%. Objective criteria for malocclusion have not been shown in earlier studies. An occlusal model before infliction of trauma is almost never available for the treatment of mandibular fracture. It is difficult to prove that normal occlusion was restored in individual patients whose preoperative occlusions were not known. We measured the postoperative occlusion using the T-scan system which allowed quantitative evaluation of occlusion, and compared the data between the patients and normal subjects as controls. Investigation of occlusal contact points in the upper and lower jaws provides important information for the diagnosis of occlusion. Qualitative analysis using inked marking strips, occlusal waxes, silicon impressions or other material is common, but methods for obtaining quantitative data for occlusal contacts have not yet been clinically established. The T-scan system was developed in 1987 by Maness et al. When a pressure sensor-incorporated, electrically conductive ink-coated polyester film is pressed by biting, the position of the tooth contact and the force of pressure at the contact point are indicated. The T-scan system is, however, disadvantageous in that the system does not respond to occlusal force below $100 \mathrm{~g}$ (threshold) and nonsensitive areas exist on the film due to the grid-pattern arrangement of pressure-sensing spots (Tokumura and Yamashita 1989). The first mentioned disadvantage, namely, the limitation in response (threshold) is negligible, because the minimum pressure needed for the stamping of inked marking strips is far larger (approximately $1,500 \mathrm{~g}$ ). The second-mentioned disadvantage, namely, the presence of nonsensitive areas, may not be a serious problem, because a proportional correlation is found between the load and indication for contact points exceeding $0.6 \mathrm{~mm}$ in diameter (Maeda et al. 1989) and because the system provides a higher 
measurement accuracy compared to conventional Prescale (Fuji Film Co., Ltd., Tokyo) (Kawazoe et al. 1988). Thus, of all currently available methods for quantitative analysis of occlusal contact, the T-scan system may be rated to be the best. In T-scan system analysis of occlusion in 93 normal subjects, Maness and Podoloff (1989) found that the normal dentition was bisymmetrical to the sagittal plane and described that the anteroposterior dynamic center of tooth contact was located at the first molar. Nabeshima et al.(1990) also studied occlusion in 90 normal subjects using the T-scan system and obtained similar findings. Analysis of the postoperative occlusion in the patients with mandibular fracture treated by our method produced similar results as those reported by Maness and Podoloff (1989) and Nabeshima et al. (1990).

Evaluation of mandibular fracture treatment from the aspect of occlusion has been little attempted (Uglešić et al. 1993). This may be attributable to the notion that since the pre-treatment original occlusion in not known, correct evaluation of the postoperative occlusion is difficult. In the study of Uglešic et al. (1993), the highest score was given to occlusion restored to a pre-injury level and the lowest score to bilaterally altered occlusion and to jaws that required reoperation. However, a concrete method for the evaluation has not been described. Their evaluation appears to lack the objectivity.

If the analytical data of occlusion after treatment do not deviate substantially from those obtained in normal subjects, our treatment method may be considered effective, at least as far as the occlusal function is concerned. Our method may not necessarily be indicated for patients with complicated fracture or bone defect. However, the method may be most desirable, when applied to fully dentate patients with mandibular body fracture in whom restoration of occlusion is deemed most important. Treatment of mandibular fractures should never be undertaken by application of the same technique to all individual patients. Choice of appropriate methodology would contribute to the improvement of postoperative "quality of life" of patients.

\section{References}

1) Cawood, J.I. (1985) Small plate osteosynthesis of mandibular fractues. Br. J. Oral Maxillofac. Surg., 23, 77-91.

2) Champy, M., Loddé, J.P., Jaeger, J.H. \& Wilk, A. (1976) Ostéosynthèses mandibulaires selon la technique de Michelet. 1. -Bases biomécaniques. Rev. Stomatol., 77, 569-576.

3) Champy, M., Loddé, J.P., Schmitt, R., Jaeger, J.H. \& Muster, D. (1978) Mandibular osteosynthesis by miniature screwed plates via a buccal approach. J. Maxillofac. Surg., 6, 14-21.

4) Dodson, T.B., Perrott, D.H., Kaban, L.B. \& Gordon, N.C. (1990) Fixation of mandibular fractures: A comparative analysis of rigid internal fixation and standard fixation techniques. J. Oral Maxillofac. Surg., 48, 362-366.

5) Katou, F. (1988) A Study on fixation of mandibular fracture without intermaxillary fixation. - Photoelastic stress analysis and clinical application- Jpn. J. Oral 
Maxillofac. Surg., 34, 635-647. (in Japanese)

6) Kawazoe, T., Tanaka, M., Ida, H., Nabeshima, F., Maeno, I., Saratani, K. \& Kawano, W. (1988) Clinical evaluation of computerized occlusal analysis by the T-Scan system. J. Osaka Odontol. Soc., 51, 1148-1154. (in Japanese)

7) Kroon, F.H.M., Mathisson, M., Cordey, J.R. \& Rahn, B.A. (1991) The use of miniplates in mandibular fractures. J. Craniomaxillofac. Surg., 19, 199-204.

8) Lindqvist, C. (1992) Discussion to experience with rigid fixation of mandibular fractures and immediate function. J. Oral Maxillofac. Surg., 50, 560-561.

9) Maeda, Y., Ohtani, T., Okada, M., Emura, I., Sogo, M., Mori, T., Yoshida, M., Nokubi, T. \& Okuno, Y. (1989) Clinical application of T-Scan system. Part 1: Sensitivity and reproducibility and its application. J. Osaka Univ. Dent. Soc., 34, 378-384. (in Japanese)

10) Maness, W.L. \& Podoloff, R. (1989) Distribution of occlusal contacts in maximum intercuspation. J. Prosthet. Dent., 62, 238-242.

11) Maness, W.L., Benjamin, M., Podoloff, R., Bobick, A. \& Golden, R. (1987) Computerized occlusal analysis: A new technology. Quintessence Int., 18, 287-292.

12) Mommaerts, M.Y. \& Engelke, W. (1986) Erfahrungen mit der Osteosynthese- Platte nach Champy/Loddé bei Unterkieferfracturen. Dtsch. Z. Mund-, Kiefer-, GesichtsChirur., 10, 94-101.

13) Nabeshima, F., Tanaka, M., Kawano, W., Saratani, K., Yanagida, M. \& Kawazoe, T. (1990) The balance of occlusal contacts during intercuspation using T-Scan System. J. Jpn. Prosthodont. Soc., 34, 340-349. (in Japanese)

14) Raveh, J., Vuillemin, T., Lädrach, K., Roux, M. \& Sutter, F. (1987) Plate osteosynthesis of 367 mandibular fractures. The unristricted indication for the intraoral approach. J. Craniomaxillofac. Surg., 15,244-253.

15) Schmelzeisen, R., McIff, T. \& Rahn, B. (1992) Further development of titanium miniplate fixation for mandibular fractures. Experience gained and questions raised from a prospective clinical pilot study with $2.0 \mathrm{~mm}$ fixation plates. J. Craniomaxillofac. Surg., 20, 251-256.

16) Spiessl, B. (1989) Internal Fixation of the Mandible. A Manual of AO/ASIF Principles. Springer-Verlag, Berlin, pp. 15-16.

17) Tokumura, T. \& Yamashita, A. (1989) A study on occlusal analysis by means of T-scan system. Part 1. Its accuracy for measurement. J. Jpn. Prosthodont. Soc., 33, 1037-1043. (in Japanese)

18) Uglešić, V., Virag, M., Aejinović, N. \& Macan, D. (1993) Evaluation of mandibular fracture treatment. J. Craniomaxillofac. Surg., 21, 251-257. 